(1)

George Fox

UNIVERSITY
Digital Commons @ George Fox University

2019

Enhancing Access for Student Nurse Athletes: Office Hours on the Road

Lorretta Krautscheid

Samuel Williams

Benjamin Kahn

Follow this and additional works at: https://digitalcommons.georgefox.edu/sn_fac

Part of the Medicine and Health Sciences Commons 


\title{
Enhancing Access for Student Nurse Athletes: Office Hours on the Road
}

\author{
Lorretta Krautscheid, Samuel Williams, and Benjamin Kahn
}

\begin{abstract}
The purpose of this education innovation was to facilitate office hour $(\mathrm{OH})$ instruction for student nurse athletes due to training schedules and off-campus travel. Effective integration of technology, learning theory, and multimedia resources provide strategies to enhance student athlete access to faculty $\mathrm{OH}$ and associated learning opportunities. Explain Everything ${ }^{\mathrm{TM}}$ software, a digital interactive whiteboard space, enables students and faculty to collaborate and learn across distance. This innovative approach enriches learning, ensuring $\mathrm{OH}$ access among student athletes.
\end{abstract}

KEY WORDS Innovation - Multimedia Resources - Office Hour Instruction - Student Athlete

S tudents attend faculty office hours $(\mathrm{OH})$ for a variety of reasons, such as asking in-depth questions, exploring challenging topics, enhancing student-faculty collaboration, and requesting additional instruction. During $\mathrm{OHs}$, faculty members provide personalized learning resources that enhance student understanding and improve learning outcomes (Acitelli, Black, \& Axelson, 2000). Student nurse athlete schedules create substantial barriers that limit opportunities to engage in and benefit from OHs. Rigorous training schedules, sports-related travel, didactic hours, and clinical practicum experiences compete with available $\mathrm{OH}$ times.

A promising strategy to overcome barriers experienced by student athletes is the use of technology to provide $\mathrm{OH}$ s on the road, a faculty-developed teaching method to enhance $\mathrm{OH}$ access and student learning. This article describes the implementation of Office Hours on the Road for student nurse athletes within higher education.

\section{INTEGRATING THEORY WITH TECHNOLOGY}

A review of relevant literature provided insights into effective $\mathrm{OH}$ instructional principles and guided the implementation of mobile $\mathrm{OH}$. During $\mathrm{OH}$, students and faculty develop insightful illustrations accompanied by rich narratives. To date, the literature recommends asking students to verbalize what they know and draw out what they

About the Authors Lorretta Krautscheid, $P h D, R N, C N E$, is an associate professor, School of Nursing, University of Portland, Portland, Oregon. Samuel Williams, MsEd, is director, Academic Technology Services and Innovation, University of Portland. Benjamin Kahn, BA, is an instructional design and technology specialist, University of Portland. For more information, contact Dr. Krautscheid at krautsch@up.edu. The authors have declared no conflict of interest. are thinking so faculty may then assess baseline understanding and gain insight about their problem-solving capacities (Acitelli et al., 2000; Griffin et al., 2014). Multimedia resources, such as Explain Everything TM (EE) software installed on mobile devices (https:// explaineverything.com), support effective $\mathrm{OH}$ instruction and promote student-faculty collaboration and access, regardless of physical distances.

EE software is an easy-to-use, interactive whiteboard tool that permits students and faculty to simultaneously draw, annotate, and narrate. The software provides audiovisual engagement and the capacity to create personalized, audiovisual recordings of learning products created during mobile $\mathrm{OH}$. Such learning products may be exported and electronically delivered to the student through a variety of platforms including email, products that enable transfer of files such as Apple's AirDrop, and course management platforms. Students may then review $\mathrm{OH}$ audiovisual learning resources as needed, supporting self-paced, personalized learning.

Faculty members who implemented Office Hours on the Road intentionally integrated the cognitive theory of multimedia instruction (Mayer, 2008; Sweller, Ayres, \& Kalyga, 2011) within OH instruction. According to Mayer, multimedia resources reduce cognitive load and optimize learning when narrations simultaneously accompany corresponding illustrations (temporal contiguity), when essential text is written next to corresponding graphics (spatial contiguity), and when signaling is used to emphasize essential information (signaling principle). Sweller et al. (2011) suggest that student learning is enhanced when extraneous load is minimized and intrinsic load is managed.

We present a case example to illustrate how the integration of multimedia resources with the cognitive theory of multimedia instruction promotes active learning, enhances understanding, and provides reusable learning products during Office Hours on the Road. Both faculty and student installed EE software (purchased by the academic 
institution) on their respective mobile devices, for example, iPad or smartphone (students were responsible for having a mobile device with wireless access). At a predetermined time, the faculty member initiated an EE collaborative project and emailed the collaboration code to the student athlete, and the student entered the collaboration code into the EE app on the mobile device. Once connected, both student and instructor could hear each other, discuss student questions and learning needs, and co-construct knowledge on the EE interactive whiteboard space.

As an example, the student spoke aloud while drawing on the whiteboard space, providing insights about thought processes. As needed, the instructor contributed both narration and illustrations within the project, drawing attention to essential points (signaling principle), facilitating congruent mental models (intrinsic load management), or remediating misunderstandings (minimizing extraneous load). Narrations with colorful illustrations were synchronously recorded (temporal contiguity). The mobile $\mathrm{OH}$ project was then saved as a digital media project, uploaded via wireless connection to a media website (Kaltura ${ }^{\mathrm{TM}}$ ), processed as a media source, and marked as "unlisted." The instructor emailed the private "unlisted" URL to the specific student, giving the student unlimited access to a personal project that could be used later for self-paced, personalized learning.

\section{CASE EXAMPLE}

A student athlete was on the road for three consecutive days and was unable to attend on-campus $\mathrm{OH}$ prior to an examination. Using wireless mobile devices and EE software, the student's instructor invited the student into a collaborative EE session. Once connected, the student's first question was about relationships between hyperkalemia and action potentials. The instructor asked the student to simultaneously narrate while drawing out a normal action potential process (temporal contiguity).

As the student drew and narrated on the mobile device, the instructor saw the drawing and heard the narration concurrently on her own mobile device. After the student finished, the instructor employed the signaling principle, using EE annotation features to draw attention to specific action potential processes. Next, she asked the student to think critically about how the action potential would be influenced in a person with hyperkalemia, such as a potassium level of $6.0 \mathrm{mEq} / \mathrm{L}$. The student verbally identified that the excess potassium was extracellular; however, when prompted to draw and narrate how the hyperkalemia would influence action potentials, the student's words and drawings demonstrated insufficient understanding of diffusion.

The instructor utilized the principle of spatial contiguity (written words next to drawings) to promote congruent mental models of diffusion, hyperkalemia, and the resulting resting membrane potential elevation. The student was then asked to use words and drawings to demonstrate understanding. Next, the student was asked to apply understanding of hyperkalemia within the context of patient care. The example was recorded, saved as an MP4 media file, and emailed to the student.

\section{STUDENT REACTIONS}

Anecdotal student comments have enthusiastically supported Office Hours on the Road as an effective teaching and learning strategy providing $\mathrm{OH}$ access, active learning, and reusable digital learning resources. Students reported EE was easy to use and were excited about using technology to demonstrate baseline understanding, receive faculty input, and create a simultaneous recording of student and faculty narrations within a media project. Students reported that opportunities for Office Hours on the Road were "much appreciated" because questions were answered in a timely manner and the media resources could be watched multiple times to rehearse complex pathological processes.

A student nurse athlete commented, "We recorded on the tablet [with collaborative EE software] and we worked on it together, and then you sent it and I was able to hear what I said and what you said and how we worked through it, that really helped with further understanding the concepts." Another student stated, "I knew that if I still had a question, I could go back and re-listen, re-watch, and answer my own question." Another student commented, "I played some parts over and over and over until I could finally see how excess potassium in the blood changes the action potential, leading to dysrhythmia. Even though I thought I knew it during office hours, I still needed to listen and re-watch it several times until I really got it." Kaltura analytics (viewing data) revealed that individual students watched their personal $\mathrm{OH}$ media project two to six times.

\section{DISCUSSION}

Although we discuss using one type of collaborative interactive whiteboard software (EE), the use of alternative whiteboard formats such as Doceri ${ }^{\mathrm{TM}}$ and ShowMe ${ }^{\mathrm{TM}}$ may also have a positive impact. As new technologies are developed, nurse educators should explore opportunities that enhance access to learning while also supporting co-construction of knowledge through collaborative studentfaculty interactions.

The Office Hours on the Road project has implications extending beyond student nurse athletes. For example, we are currently teaching learning skills specialists (athletic department tutors) how to optimally integrate the cognitive theory of multimedia instruction with technology, enhancing both mobile tutoring and face-to-face tutor sessions. We anticipate that these teaching strategies will positively influence learning outcomes among student athletes, inspiring recommendations for both education practice and research.

\section{REFERENCES}

Acitelli, L. K., Black, B., \& Axelson, E. (2000). Learning and teaching during office hours. GSI guidebook (7th ed.). Ann Arbor, Ml: Center for Research on Learning and Teaching, University of Michigan at Ann Arbor.

Griffin, W., Cohen, S., Berndtson, R., Burson, K., Camper, M., \& Chen, Y. (2014). Starting the conversation: An exploratory study of factors that influence student office hour use. College Teaching, 62(3), 94-99.

Mayer, R. E. (2008). Applying the science of learning: Evidence-based principles for the design of multimedia instruction. American Psychologist, 63(8), 760-769. doi:10.1037/0003-066X.63.8.769

Sweller, J., Ayres, P., \& Kalyga, S. (2011). Cognitive load theory. New York, NY: Springer. 